\title{
Influence of Wasting and Stunting at the Onset of the Rainy Season on Subsequent Malaria Morbidity among Rural Preschool Children in Senegal
}

\author{
Florie Fillol,* Amandine Cournil, Denis Boulanger, Badara Cissé, Cheikh Sokhna, Geoffrey Targett, \\ Jean-François Trape, François Simondon, Brian Greenwood, and Kirsten B. Simondon \\ Epidemiology and Prevention Research Unit, Institut de Recherche pour le Développement, Montpellier, France; Department \\ of Parasitology, Université Cheikh Anta Diop, Dakar, Senegal; Tropical Malaria Research Unit, Institut de Recherche pour le \\ Développement, Dakar, Senegal; Department of Infectious and Tropical Disease, London School of Hygiene and Tropical \\ Medicine, London, United Kingdom
}

\begin{abstract}
In sub-Saharan Africa, malaria and malnutrition are major causes of morbidity and mortality in children less than five years of age. To explore the impact of malnutrition on subsequent susceptibility to malaria, a cohort of 874 rural preschool children in Senegal was followed-up during one malaria transmission season from July through December. Data on nutritional status and Plasmodium falciparum parasitemia were collected at baseline. Malaria morbidity was monitored through weekly home visits. Wasted children (weight-for-height $\mathrm{z}$-score $<-2$ ) were at lower risk of having at least one subsequent clinical malaria attack (odds ratio $=0.33 ; 95 \%$ confidence interval $=0.13-0.81, P=0.02$ ), whereas stunting (height-for-age z-score $<-2$ ) or being underweight (weight-for-age z-score $<-2$ ) was not associated with clinical malaria. Although non-biological explanations such as overprotection of wasted children by their mothers should be considered, immunomodulation according to nutritional status could explain the lower risk of malaria attack among wasted children.
\end{abstract}

\section{INTRODUCTION}

Malaria and malnutrition are two major causes of childhood mortality in sub-Saharan Africa. Malnutrition is highly prevalent in children less than five years of age living in this area: $38 \%$ with stunting (height-for-age $\mathrm{z}$-score $<-2$ of an international growth reference), $28 \%$ are underweight (weightfor-age $\mathrm{z}$-score $<-2$ ), and wasting (weight-for-height $\mathrm{z}$-score $<-2$ ) affects $9 \%$ of these children. ${ }^{1}$ It is now widely admitted that malnutrition exposes children less than five years of age to a higher risk of death. ${ }^{2-4}$ Plasmodium falciparum infection is another major determinant of childhood mortality: 800,000 preschool children die of malaria each year, and $75 \%$ of these deaths occur in children in Africa. ${ }^{1,5}$ Among survivors, malaria infection as well as chronic malnutrition (stunting) can result in impairment of cognitive capacities, school performance and later, in decreased physical work capacity, which has an impact on the economic development of societies. ${ }^{6-8}$

The relationship between malaria and nutrition has been investigated for many years. Although a number of observations have indicated a deleterious effect of malaria on nutritional status, ${ }^{9-11}$ it is still unclear whether and how nutritional status influences malaria-related morbidity. Although some studies have shown a trend to lower malaria-related morbidity among wasted children, none have reported any significant association between wasting and subsequent clinical malaria. ${ }^{12,13}$ For stunting, results are conflicting. One longitudinal study showed that stunting increased the risk of clinical malaria among rural children in The Gambia, ${ }^{12}$ and a trial in Papua New Guinea showed that stunting protected children from $P$. falciparum malaria. ${ }^{14}$ Several older studies based on hospital admissions for severe malaria suggested that the condition of being underweight protected children from malaria infection. ${ }^{15-17}$ However, recent community-based studies did not confirm such an association. ${ }^{13,18,19}$ These discrepant results

* Address correspondence to Florie Fillol, Epidémiologie et Prévention, Institut de Recherche pour le Développement, Unité de Recherche 024, 911 Avenue Agropolis, BP 64501, 34394 Montpellier, France.E-mail: fillol@mpl.ird.fr demonstrate the need for further studies that would include a longitudinal assessment of the relationship between malnutrition and the risk of subsequent malaria morbidity.

In 2002, a randomized, double-blind, placebo-controlled intervention study of seasonal intermittent preventive treatment (IPT) of malaria was conducted in a cohort of 2-59-month-old children living in a rural area of Senegal where transmission is highly seasonal. These children received either one monthly dose of artesunate plus one dose of sulfadoxinepyrimethamine or two placebos during the three months of the peak malaria transmission season (September, October, and November). The intervention was highly successful: the risk of a malaria clinical attack was reduced by $86 \% .^{20}$

An observational follow-up study was conducted in 2003 with the aim of assessing the risk of a rebound effect after ending IPT; all malaria episodes were closely monitored. The analysis presented in this report was conducted to assess whether childhood malnutrition (stunting, wasting, and underweight) at the beginning of the rainy season was a determinant of susceptibility to clinical malaria in this context of highly seasonal malaria.

\section{MATERIALS AND METHODS}

Study design. This study was a longitudinal observational follow-up study without chemoprevention for 25 weeks from mid-July to the end of December 2003.

Study area and population. The study was performed in Niakhar, a rural district of Senegal $150 \mathrm{~km}$ from the capital of Dakar. This area contains 30 villages within an area of $230 \mathrm{~km}^{2}$. Eleven of these were selected for participation in the trial on the grounds of accessibility, size, and interest.

The rainy season takes place from late June-early July through October. No rivers and few permanent waterholes are found in the area. Consequently, $P$. falciparum malaria transmission occurs from August through October. The average entomologic inoculation rate is 10 infective bites per person per year, and the principal vector is Anophaele gambiae ss. ${ }^{21}$

Since 1983, demographic surveillance has been maintained in the study area, which provides precise dates of births and deaths. 
The mortality rate for children 1-4 years of age was 144/1,000 live births during 1994-1999.22 Malaria accounts for $25 \%$ of all deaths in 1-4-year-old children. ${ }^{23}$ The nutritional status of infants and preschool children is largely dependent on season, with the greatest weight-for-height and height-for-age at the end of the dry season (March-May) and lowest averages after the end of the rainy season (October-November). ${ }^{24}$

Participants. To be included in this study, children had to be enrolled in the IPT trial in 2002. Inclusion criteria have been described. ${ }^{20}$ A total of 984 children were included in July 2003. Data on anthropometric measurements, hemoglobin status, and $P$. falciparum parasitemia were collected at the inclusion. Children with a hemoglobin concentration $<7 \mathrm{~g} / \mathrm{dL}$ and children admitted to an ad hoc nutrition rehabilitation center were provided malaria prophylaxis upon the recommendation of the Data Safety Monitoring Board. Consequently, they were excluded from the analysis, as were children with incomplete anthropometric data and those absent at the time of the home visit in July 2003. The remaining 874 children were included in the analysis (Figure 1).

Anthropometric measurements. Anthropometric data were collected at health centers by two trained measurers in July

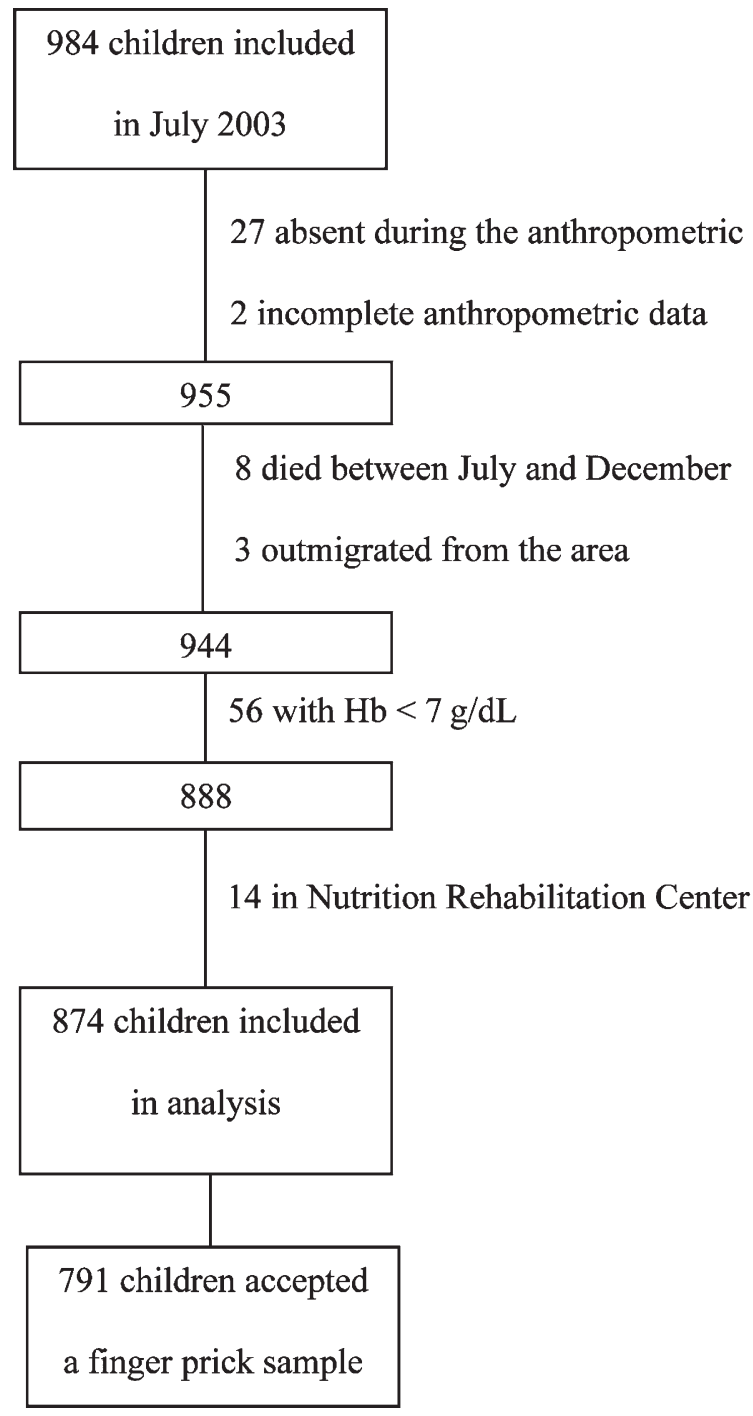

FIGURE 1. Flow chart of the study. and December 2003, in accordance with internationally recommended procedures. ${ }^{25}$ Weight measurements were taken using baby scales (Seca, Hamburg, Germany) precise to the nearest $10 \mathrm{~g}$ for children weighing $<16 \mathrm{~kg}$, and an electronic scale (Téfal, Paris, France) precise to the nearest $100 \mathrm{~g}$ for older children. Recumbent length measurements were taken for children less than two years of age, and standing height was measured beyond that age. Measurements were precise to the nearest millimeter. Height and length measurements were taken twice at each visit and the average was used for analysis. Arm circumference was measured on the left arm. For a value $<12.5 \mathrm{~cm}$ or clinical signs of acute malnutrition, the mother was strongly advised to bring the child to the ad hoc nutrition rehabilitation center and informed that the child would be treated free of charge. A daily-updated register enabled identification of admitted children including their Institut de Recherche pour le Développement database identification number.

Sociodemographic data (child's age, sex, village and hamlet of residence, maternal age, religion, formal school education, and professional activity) were taken from the Niakhar study area database.

Case detection and management. Malaria morbidity was monitored from mid-July to the end of December 2003 by active surveillance through home visits every week and by passive detection of study children who came to one of the three health centers in the study area. All illnesses suspected to be malaria were recorded and registered by a trained health worker. At each home visit, a blood film was prepared if the axillary temperature was $\geq 37.5^{\circ} \mathrm{C}$, or if a history of fever or vomiting during the previous 24 hours was reported. Results of the blood film examination were usually available within two hours. Following a recommendation of the Senegalese Ethical Review Committee, children with clinical malaria symptoms and parasitemia at any density were treated with antimalarial drugs. For this treatment, the children were included in a randomized simple blind open study that investigated the efficacy of three antimalarial combinations therapies: artesunate plus amodiaquine (AS plus AQ), artesunate plus sulfadoxinepyrimethamine (AS plus SP), or sulfadoxine-pyrimethamine plus amodiaquine (SP plus AQ). Thus, all three combinations contained at least one drug with a long half-life. Efficacy did not differ significantly between the three combinations of antimalarial drugs.

Statistical analysis. The nutritional indicators height-for-age (HAZ), weight-for-height (WHZ), and weight-for-age (WAZ) were computed in z-scores of the World Health Organization/ National Center for Health Statistics reference by using Epi Info version 6 software (Centers for Disease Control and Prevention, Atlanta, GA). Stunting, wasting, and being underweight were defined for values $<-2$ for HAZ, WHZ, and WAZ, respectively. At the assessment in July 2003, children were allocated to one of five age strata: 12-23.9, 24-35.9, 36-47.9, 48-60, and > 60 months, respectively.

A clinical malaria attack was defined as an illness with a body temperature $\geq 37.5^{\circ} \mathrm{C}$, a history of fever or vomiting within the previous 24 hours, or both, with no other obvious cause for fever or vomiting and the presence of $P$. falciparum asexual stage $\geq 3,000$ parasites/ $\mu \mathrm{L}$. The definition used for the analysis was more stringent than that used to initiate antimalarial treatment so as to increase its specificity (i.e., avoid falsepositive results). Malaria attacks were classified binomially as 
any versus none, i.e., for persons with more than one attack, only the first was considered in the analysis.

Children with parasitemia $<3,000 / \mu \mathrm{L}$ at the first fever episode remained in the risk set, although they had received presumptive antimalarial treatment. Consequently, a presumptive treatment variable was created to take into account its effect on their subsequent risk of clinical malaria. The presumptive treatment variable was coded as yes or no. Yes was attributed to children whose first fever episode was not confirmed as a clinical malaria attack. No was attributed to children who did not have any recorded fever episodes during follow-up and to children whose first fever episode corresponded to a clinical malaria attack (because they were withdrawn from the risk set at that time).

Chi-square tests were used to assess the association between the occurrence of at least one clinical malaria episode during the 2003 rainy season and parasitemia in July 2003 with malnutrition indicators and categoric background factors.

Parasite densities were normalized by log-transformation and geometric means, and 95\% confidence intervals (CIs) were calculated. A parasitemia threshold was determined as the geometric mean: low-density parasitemia was $<300$ parasites/ $\mu \mathrm{L}$ and high-density parasitemia was above this threshold. The risk of high-density parasitemia by nutritional status was estimated by using a multivariate logistic regression model adjusting for background factors.

Mixed logistic regressions (NLMIXED procedure, SAS version 8.2; SAS Institute, Cary, NC) were used to model the risk of a clinical malaria attack on the basis of the occurrence of malnutrition (stunting, wasting, or being underweight) adjusting for potential confounders and background factors: age (in five groups), sex and presumptive treatment as fixed effects, and place of residence as a random effect. For this analysis, hamlets were introduced as place of residence instead of villages because small geographic units better take into account geographic heterogeneity of malaria exposure. ${ }^{21}$ The best model among different covariance structures was selected using a chi-square test of the difference between the -2 loglikelihood values. Covariates were retained if they were significant at the $5 \%$ level. SAS version 8.2 software was used for all analyses.

Ethics. The study protocol was reviewed and approved by the ethical review committees of the Senegalese Ministry of Health and the London School of Hygiene and Tropical Medicine.

\section{RESULTS}

In July 2003, the ages of the 874 study children ranged from 12 to 70 months, with a mean of 41.9 months (Table 1). Maternal characteristics (age, occupation, and school education) were not significantly associated with risk of malaria.

Mean anthropometric indicators varied significantly by age $(P<0.001, P<0.0001$, and $P=0.03$ for HAZ, WHZ, and WAZ, respectively), but not by sex or village of residence. Children 36-48 months of age had significant lower mean HAZ than younger or older children (Bonferroni's adjustment) whereas mean WHZ and mean WAZ were lowest among children 12-24 months of age. The prevalence of malnutrition (wasting, stunting, and being underweight) at baseline was moderate (Table 1).

Risk of clinical malaria attacks by background factors. Sixtythree percent of children had clinical malaria on at least one
TABLE 1

Characteristics of rural preschool children in Senegal included in the 2003 cohort study*

\begin{tabular}{lc}
\hline \multicolumn{1}{c}{ Characteristic } & Value $(\mathrm{n}=874)$ \\
\hline Child's age (months) & \\
12-23.9 & $167(19.1)$ \\
$24-35.9$ & $180(20.6)$ \\
$36-47.9$ & $180(20.6)$ \\
$48-60$ & $192(22.0)$ \\
$>60$ & $155(17.7)$ \\
Mean \pm SD & $41.9 \pm 16.8$ \\
Sex & \\
Female & $452(51.7)$ \\
Male & $422(48.3)$ \\
Village & \\
1 & $26(3.0)$ \\
2 & $85(9.7)$ \\
3 & $53(6.1)$ \\
4 & $46(5.3)$ \\
5 & $73(8.4)$ \\
6 & $116(13.3)$ \\
7 & $77(8.8)$ \\
8 & $143(16.4)$ \\
9 & $107(12.2)$ \\
10 & $49(5.6)$ \\
11 & $99(11.3)$ \\
Nutritional status $\dagger$ & \\
Height-for-age (z-score) & $-1.09 \pm 1.00$ \\
Weight-for-age (z-score) & $-0.99 \pm 0.92$ \\
Weight-for-height (z-score) & $-0.40 \pm 0.88$ \\
Prevalence of malnutrition $\dagger$ & \\
Stunting & $165(18.9)$ \\
Underweight & $109(12.5)$ \\
Wasting & $27(3.1)$ \\
Positive for Plasmodium falciparum $\dagger$ & $210(26.5) \ddagger$ \\
Clinical malaria attack $\$$ & \\
0 & $322(36.8)$ \\
1 & $326(37.3)$ \\
2 & $168(19.2)$ \\
3 & $54(6.2)$ \\
$\geq 1$ & $4(0.5)$ \\
$*$ Values are no. (\%) or mean \pm SD. & $552(63.2)$ \\
\hline At inclusion in July 2003. & \\
$\$$ Data missing for 83 children. & \\
& \\
&
\end{tabular}

occasion during the transmission season (Table 1). The prevalence of clinical malaria varied strongly by age and village $(P<0.0001$ for both), but not by sex; it was highest among children 24-48 months of age (Table 2). Moreover, considering the effect of presumptive treatment, the risk of clinical malaria attack was significantly lower in children treated for a previous presumptive attack than in children who did not receive presumptive treatment (odds ratio $[\mathrm{OR}]=0.26$, $P<0.0001$; Table 2).

Risk of clinical malaria attacks by nutritional status at baseline. The risk of malaria was not significantly greater in stunted children than in their non-stunted counterparts $(P=0.59)$, but it was significantly lower in wasted children than in non-wasted children: less than half of wasted children had one malaria attack compared with almost two-thirds of their non-wasted counterparts $(P=0.014$; Table 2). Similar results were found for being underweight $(P=0.04)$.

To assess the risk of clinical malaria attack by nutritional status independent of potential confounders, mixed models were run for stunting, wasting, and being underweight separately. Wasting appeared to be independently and significantly 
TABLE 2

Prevalence of clinical malaria attacks in rural children in Senegal according to background factors

\begin{tabular}{|c|c|c|}
\hline Variable & $\geq 1$ Malaria attack $(\%)$ & $P^{*}$ \\
\hline \multicolumn{3}{|l|}{ Sex } \\
\hline Female & 65.0 & 0.23 \\
\hline Male & 61.1 & \\
\hline \multicolumn{3}{|l|}{ Child's age (months) $\dagger$} \\
\hline $12-23.9$ & 59.3 & $<0.0001$ \\
\hline $24-35.9$ & 77.2 & \\
\hline $36-47.9$ & 69.4 & \\
\hline $48-60$ & 56.3 & \\
\hline$>60$ & 52.3 & \\
\hline \multicolumn{3}{|l|}{ Village } \\
\hline 1 & 73.1 & $<0.0001$ \\
\hline 2 & 29.4 & \\
\hline 3 & 56.6 & \\
\hline 4 & 45.7 & \\
\hline 5 & 53.4 & \\
\hline 6 & 72.4 & \\
\hline 7 & 63.6 & \\
\hline 8 & 76.9 & \\
\hline 9 & 73.8 & \\
\hline 10 & 57.1 & \\
\hline 11 & 68.7 & \\
\hline \multicolumn{3}{|c|}{$\begin{array}{l}\text { Presumptive antimalarial treatment } \\
\text { prior to first clinical attack (if any) } \ddagger\end{array}$} \\
\hline No§ & 69.29 & $<0.0001$ \\
\hline Yes\# & $35.9 * *$ & \\
\hline \multicolumn{3}{|l|}{ Malnutrition $\dagger$} \\
\hline Stunted & 61.2 & 0.59 \\
\hline Not stunted & 63.6 & \\
\hline Wasted & 40.7 & 0.014 \\
\hline Not wasted & 63.9 & \\
\hline Underweight & 54.1 & 0.04 \\
\hline Not underweight & 64.4 & \\
\hline All & 63.2 & \\
\hline
\end{tabular}

* By chi-square test

$\dagger$ At inclusion in July 2003

$\doteqdot$ From July through December 2003

$\S \mathrm{No}=$ attributed to children who did not have any recorded fever episodes during follow-up $(\mathrm{n}=220)$ or to children whose first fever episode corresponded to clinical malaria $(\mathrm{n}=495)$. II A total of 495 of the 715 children who did not receive antimalarial presumptive treatment had at least one clinical malaria attack.

\# Yes = attributed to children who received antimalarial treatment although their first fever episode was not confirmed as a clinical malaria attack $(\mathrm{n}=159)$.

** A total of 57 of the 159 children who received antimalarial presumptive treatment had at least one clinical malaria attack.

associated with clinical malaria, as did age, previous presumptive antimalarial treatment, and place of residence (Table 3). Although the prevalence of wasting was low in July 2003 (i.e., 3.1\%), wasted children were at significantly lower risk of having a malaria attack during the following transmission season $(\mathrm{OR}=0.33,95 \% \mathrm{CI}=0.13-0.81, P=0.02)$. As expected, presumptive antimalarial treatment was highly protective, decreasing by $85 \%$ the probability of having a malaria attack (Table 3). Finally, the random effect of place of residence was significant $(P=0.003)$, indicating spatial heterogeneity of malaria exposure.

In mixed models, stunting and underweight were not significantly associated with the risk of malaria $(P=0.44$ and $P=0.07$, respectively). When considering stunting for children less than versus those greater than two years of age separately, results were unchanged.

Prevalence of parasitemia in July 2003. At the onset of surveillance, $26.5 \%$ of the children had $P$. falciparum parasitemia (Table 1). We did not observe any significant relationship between nutritional status and the risk of having parasitemia.
TABLE 3

Risk of clinical malaria attack from July to December 2003 in rural children in Senegal according to potential risk factors

\begin{tabular}{lccc}
\hline & \multicolumn{3}{c}{$\geq 1$ Malaria attack } \\
\cline { 2 - 4 } & $\begin{array}{c}\text { Parameter } \\
\text { estimate (SE) }\end{array}$ & $P$ & $\begin{array}{c}\text { Adjusted odds ratio } \\
\text { (95\% confidence } \\
\text { interval) }\end{array}$ \\
\hline $\begin{array}{c}\text { Fixed effects } \\
\quad \text { Intercept }\end{array}$ & $0.90(0.23)$ & 0.0002 & - \\
$\quad \begin{array}{l}\text { Wasting (wasted vs. } \\
\quad \text { not wasted) }\end{array}$ & $-1.10(0.45)$ & 0.02 & $0.33(0.13-0.81)$ \\
$\begin{array}{l}\text { Presumptive treatment } \\
\quad \text { treated vs. untreated) }\end{array}$ & $-1.87(0.22)$ & $<0.0001$ & $0.15(0.10-0.24)$ \\
Age group (months) & - & - & - \\
$\quad$ 12-23.9 & - & - & 1.00 \\
$\quad$ 24-35.9 & $0.84(0.27)$ & 0.003 & $2.32(1.34-4.00)$ \\
$\quad$ 36-47.9 & $0.43(0.26)$ & 0.1 & $1.53(0.91-2.57)$ \\
$\quad$ 48-60 & $-0.25(0.25)$ & 0.3 & $0.78(0.47-1.28)$ \\
$\quad$ 60 & $-0.46(0.26)$ & 0.08 & $0.63(0.37-1.06)$ \\
Random effect & & & - \\
$\quad$ Place of residence* & $0.72(0.23)$ & 0.003 & - \\
\hline * Hamlet & & &
\end{tabular}

*Hamlet.

Among parasitemic children, the geometric mean of parasitemia was 300 parasites/ $\mu \mathrm{L}$ and varied by sex (girls had a lower mean than boys; $P=0.008)$ and village $(P=0.004)$, but not by age. This geometric mean was used as threshold to define high-density parasitemia. In adjusted analyses, wasting or being underweight was not associated with high-density parasitemia $(\mathrm{OR}=0.48,95 \% \mathrm{CI}=0.04-5.34, P=0.55$ and $\mathrm{OR}$ $=0.96,95 \% \mathrm{CI}=0.35-2.66, P=0.94$, respectively), whereas stunted children had a significantly greater risk of being highly parasitemic $(\mathrm{OR}=2.42,95 \% \mathrm{CI}=1.12-5.24, P=0.03)$.

\section{DISCUSSION}

In this study, we examined the effect of childhood malnutrition, measured at the beginning of the rainy season, upon the risk of subsequent malaria morbidity in an area of mesoendemic and highly seasonal malaria transmission in Senegal. Our results show that wasting (low weight-for-height) was protective against clinical malaria attack in preschool children, whereas stunting or being underweight were not significantly associated with the risk of having clinical malaria.

This study had several strengths. Anthropometric measures were taken by well-trained experienced field workers. Because of the longitudinal study design and active and passive case detection, data collected enabled a complete description of malaria morbidity during the follow-up from mid-July to the end of December 2003.

The low number of wasted children is a limitation to the study. Another limitation is that children who were excluded from the analysis because of low hemoglobin concentration upon recruitment or hospitalization with malnutrition during follow-up had a higher prevalence of stunting and underweight than their included counterparts $(50.0 \%$ versus $18.9 \%$; $P<0.0001 ; 31.4$ versus $12.5 \% ; P<0.0001$; and 4.3 versus $3.1 \%$; $P=0.6$, for stunting, being underweight, and wasting, respectively). To assess the impact of this selection bias, these 70 children were included in additional logistic mixed models (all with the presumptive treatment variable set to 1 because they had benefited from systematic malaria prophylaxis). The association between malnutrition (wasting, stunting, and being underweight) and subsequent clinical malaria morbidity remained unchanged. 
We also tested whether the lower risk of clinical malaria among wasted children could be explained by a greater general level of non-specific morbidity, i.e., by repeated clinical symptoms evocative of malaria, such as fever and vomiting, prompting the search for $P$. falciparum carriage and presumptive antimalarial treatment. Among wasted children, $14.8 \%$ had received at least one presumptive treatment against malaria for which the diagnosis of clinical malaria was later rejected because of their low parasitemia compared with $18.3 \%$ of their non-wasted counterparts $(P=0.64)$. Thus, wasted children did not benefit from more presumptive treatment than other children.

Wasted children were at lower risk of having clinical malaria. We acknowledge that the prevalence of wasting was low $(3.1 \%$ in July 2003 compared with $7.6 \%$ in September 2002). The prevalence of wasting varies strongly by season in this part of Senegal for infants as well as for children $\geq 3$ years of age. ${ }^{26,27}$ An anthropometric assessment in SeptemberOctober would have yielded more wasted children. However, part of this wasting would probably have been an outcome of clinical malaria attacks, thus confronting us with the problem of reverse causality.

To the best of our knowledge, no previously published study has described a significantly lower risk of clinical malaria among wasted children. However, two studies in The Gambia showed trends toward lower malaria-related morbidity among children with low weight-for-height. In their prospective study, Deen and others found that wasted children tended to have less clinical malaria (relative risk $[\mathrm{RR}]=0.87,95 \% \mathrm{CI}=0.69-$ 1.10). ${ }^{12}$ In another Gambian study, 1-4-year-old children who did not have malaria had slightly lower mean weight-for-height at baseline $(\mathrm{WHZ}=-1.03$ versus $\mathrm{WHZ}=-1.18)$, although the difference was not statistically significant. ${ }^{13}$

Most other studies dealing with this subject were conducted in areas with intense perennial transmission of malaria. This difference could explain in part the discrepancy in results because acquired immunity and host resistance vary in their pattern of malaria transmission..$^{28,29}$

With regard to stunting, Deen and others found that chronically malnourished children in The Gambia were at higher risk of having a malaria attack $(\mathrm{RR}=1.35,95 \%$ $\mathrm{CI}=1.08-1.69) .{ }^{12}$ In a study in Papua New Guinea, stunting protected children from $P$. falciparum malaria (one unit increase in HAZ increased $P$. falciparum malaria attacks by $13 \%) .{ }^{14}$ Our findings did not indicate an association between stunting and susceptibility to malaria. However, stunted children were at significantly higher risk of highdensity parasitemia at the onset of the rainy season, a finding consistent with the increased risk of high-density parasitemia among children with low height-for-age in Kenya $(\mathrm{OR}=1.84, P<0.0001){ }^{30}$

Several hypotheses can be considered to explain the lower risk of clinical malaria among wasted children found in the present analysis. The first hypothesis suggests that the relationship is explained by the mothers' behavior. Studies conducted in this population have shown that mothers are able to correctly evaluate their children's nutritional status and that they attempt to mitigate the negative effects of malnutrition on survival, notably by prolonging the duration of breastfeeding of high-risk children. ${ }^{24,31}$ Thus, it is possible that mothers tend to use preventive measures (chemoprophylaxis, bed nets) more frequently for wasted children.
An alternative, biological hypothesis is that childhood immunity to malaria is modulated by nutritional status. It is now widely recognized that nutrition plays an important role in modulation of anti-pathogen immunity, and numerous studies have shown that micronutrients are significant immunomodulators. ${ }^{32,33}$ Most studies have demonstrated a deleterious effect of malnutrition on the appropriate immune response to infection, ${ }^{34,35}$ but a few have supported the assertion that some micronutrient deficiencies such as that of riboflavin, vitamin $\mathrm{E}$, or iron might, conversely, protect against malaria infection. ${ }^{36}$

Some evidence is currently considered to support a deleterious effect of iron supplementation in malaria-endemic area when adequate anti-malaria prophylaxis is not associated. ${ }^{37}$ Several studies have shown that malaria morbidity, in an area of high malaria transmission, was exacerbated when children received iron supplementation. ${ }^{38,39}$ Another trial conducted in Kenya also suggests that iron deficiency might protect children from malaria. ${ }^{40}$ In the present study, hemoglobin concentration was assessed in July 2003 for 864 children. In additional analyses, we have investigated if anemia, as possibly associated with iron deficiency, may act as a confounder in the relationship between wasting and susceptibility to malaria. We did not find any significant association between hemoglobin concentration and wasting or WHZ.

In a cohort of 1-10-year-old children in Papua New Guinea, Genton and others observed a protective effect of low heightfor-age against malaria attacks. Conversely, they found a significant increase in production of interferon- $\gamma$ in response to stimulation by specific malarial antigens in stunted children compared than in their non-stunted counterparts. ${ }^{14}$ Thus, they suggested that this increase might explain, in part, the protection of stunted children. These findings demonstrate the importance of investigating the mechanisms of the antimalarial immune response in relation to childhood malnutrition.

In conclusion, the present study suggests that wasted preschool children are at lower risk of having subsequent clinical malaria, whereas no association was found with stunting. This apparent protection of wasted children from clinical malaria might be caused by a modulation of their immune response. To investigate this hypothesis, analyses aimed at assessing the antimalaria antibody response of children according to their nutritional status are in progress.

Received July 11, 2008. Accepted for publication October 8, 2008.

Acknowledgments: We thank El Hadj Ba for assessment of parasitemia; Ernest Faye for field supervision; the malaria field team for monitoring of malaria morbidity; Tofène Ndiaye, Amady Ndiaye, and Bassirou Fall for assessment of anthropometric measurements; Adama Marra for help with identification of eligible children and data management; Frederic Capuano and Cécile Cames for preliminary data analysis; and Jo Lines and Neal Alexander for contributions to the design of the study.

Financial support: The study was supported by the Gates Malaria Partnership, which receives support from the Bill and Belinda Gates Foundation and the London School of Hygiene and Tropical Medicine Department for International Development Malaria Knowledge Programme, and by the Institut de Recherche pour le Développement.

Authors' addresses: Florie Fillol, Amandine Cournil, Denis Boulanger, François Simondon, and Kirsten B. Simondon, Epidémiologie et Prévention, Institut de Recherche pour le Développement, Unité de Recherche 024, 911 Avenue Agropolis, BP 64501, 34394 Montpellier, France,E-mails: fillol@mpl.ird.fr, cournil@mpl.ird.fr, boulanger@mpl .ird.fr, simondof@mpl.ird.fr, and kirsten@mpl.ird.fr. Badara Cissé, 
Département de Parasitologie, Université Cheikh Anta Diop, BP 5005, Dakar, Sénégal, E-mail: badara.cisse@lshtm.ac.uk. Cheikh Sokhna, Unité Mixte de Recherche 198, Institut de Recherche pour le Développement, BP 1386, CP 18524, Dakar Senegal, E-mail: cheikh .sokhna@ird.sn. Geoffrey Targett, London School of Hygiene and Tropical Medicine, M LG4, 50 Bedford Square, London WC1B 3DP, United Kingdom, E-mail: geoff.targett@lshtm.ac.uk. Jean-François Trape, Unité Mixte de Recherche 198, Institut de Recherche pour le Développement, Paludologie Afro-Tropicale, BP 1386, CP 18524, Dakar Senegal, E-mail: jean-françois.trape@ird.sn. Brian Greenwood, London School of Hygiene and Tropical Medicine, Room 400, Keppel Street, London WC1E 7HT, United Kingdom, E-mail: brian .greenwood@lshtm.ac.uk.

\section{REFERENCES}

1. UNICEF, 2007. Progress for Children: A World Fit for Children: Statistical Review. New York: United Nations, 19-24.

2. Pelletier DL, 1994. The potentiating effects of malnutrition on child mortality: epidemiologic evidence and policy implications. Nutr Rev 52: 409-415.

3. Fawzi WW, Herrera MG, Spiegelman DL, el Amin A, Nestel P, Mohamed KA, 1997. A prospective study of malnutrition in relation to child mortality in the Sudan. Am J Clin Nutr 65: 1062-1069.

4. Man WD, Weber M, Palmer A, Schneider G, Wadda R, Jaffar S, Mulholland EK, Greenwood BM, 1998. Nutritional status of children admitted to hospital with different diseases and its relationship to outcome in The Gambia, West Africa. Trop Med Int Health 3: 678-686.

5. Breman JG, 2001. The ears of the hippopotamus: manifestations, determinants, and estimates of the malaria burden. Am J Trop Med Hyg 64: 1-11.

6. Fernando D, Wickremasinghe R, Mendis KN, Wickremasinghe AR, 2003. Cognitive performance at school entry of children living in malaria-endemic areas of Sri Lanka. Trans $R$ Soc Trop Med Hyg 97: 161-165.

7. Branca F, Ferrari M, 2002. Impact of micronutrient deficiencies on growth: the stunting syndrome. Ann Nutr Metab 46 (Suppl 1): $8-17$.

8. Martorell R, Rivera J, Kaplowitz H, Pollitt E, 1992. Long-term consequences of growth retardation during early childhood. Hernandez M, Argente J, eds. Human Growth: Basic and Clinical Aspects. Amsterdam: Elsevier Science Publishers B.V., 143-149.

9. ter Kuile FO, Terlouw DJ, Phillips-Howard PA, Hawley WA, Friedman JF, Kolczak MS, Kariuki SK, Shi YP, Kwena AM, Vulule JM, Nahlen BL, 2003. Impact of permethrin-treated bed nets on malaria and all-cause morbidity in young children in an area of intense perennial malaria transmission in western Kenya: cross-sectional survey. Am J Trop Med Hyg 68: 100-107.

10. Bradley-Moore AM, Greenwood BM, Bradley AK, Kirkwood BR, Gilles HM, 1985. Malaria chemoprophylaxis with chloroquine in young Nigerian children. III. Its effect on nutrition. Ann Trop Med Parasitol 79: 575-584.

11. Snow RW, Molyneux CS, Njeru EK, Omumbo J, Nevill CG, Muniu E, Marsh K, 1997. The effects of malaria control on nutritional status in infancy. Acta Trop 65: 1-10.

12. Deen JL, Walraven GE, von Seidlein L, 2002. Increased risk for malaria in chronically malnourished children under 5 years of age in rural Gambia. J Trop Pediatr 48: 78-83.

13. Snow RW, Byass P, Shenton FC, Greenwood BM, 1991. The relationship between anthropometric measurements and measurements of iron status and susceptibility to malaria in Gambian children. Trans R Soc Trop Med Hyg 85: 584-589.

14. Genton B, Al-Yaman F, Ginny M, Taraika J, Alpers MP, 1998. Relation of anthropometry to malaria morbidity and immunity in Papua New Guinean children. Am J Clin Nutr 68: 734-741.

15. Hendrickse RG, Hasan AH, Olumide LO, Akinkunmi A, 1971. Malaria in early childhood. An investigation of five hundred seriously ill children in whom a "clinical" diagnosis of malaria was made on admission to the children's emergency room at University College Hospital, Ibadan. Ann Trop Med Parasitol 65: $1-20$.
16. Ahmad SH, Moonis R, Shahab T, Khan HM, Jilani T, 1985. Effect of nutritional status on total parasite count in malaria. Indian $J$ Pediatr 52: 285-287.

17. Murray MJ, Murray AB, Murray NJ, Murray MB, 1978. Diet and cerebral malaria: the effect of famine and refeeding. Am J Clin Nutr 31: 57-61.

18. Muller O, Garenne M, Kouyate B, Becher H, 2003. The association between protein-energy malnutrition, malaria morbidity and all-cause mortality in West African children. Trop Med Int Health 8: 507-511.

19. Tshikuka JG, Gray-Donald K, Scott M, Olela KN, 1997. Relationship of childhood protein-energy malnutrition and parasite infections in an urban African setting. Trop Med Int Health 2: 374-382.

20. Cisse B, Sokhna C, Boulanger D, Milet J, Ba el H, Richardson K, Hallett R, Sutherland C, Simondon K, Simondon F, Alexander N, Gaye O, Targett G, Lines J, Greenwood B, Trape JF, 2006. Seasonal intermittent preventive treatment with artesunate and sulfadoxine-pyrimethamine for prevention of malaria in Senegalese children: a randomised, placebo-controlled, doubleblind trial. Lancet 367: 659-667.

21. Robert V, Dieng H, Lochouran L, Traore SF, Trape JF, Simondon F, Fontenille D, 1998. Malaria transmission in the rural zone of Niakhar, Senegal. Trop Med Int Health 3: 667-677.

22. Delaunay V, Etard JF, Preziosi MP, Marra A, Simondon F, 2001. Decline of infant and child mortality rates in rural Senegal over a 37-year period (1963-1999). Int J Epidemiol 30: 1286-1293; discussion 1294-1295.

23. Etard JF, Le Hesran JY, Diallo A, Diallo JP, Ndiaye JL, Delaunay V, 2004. Childhood mortality and probable causes of death using verbal autopsy in Niakhar, Senegal, 1989-2000. Int $J$ Epidemiol 33: 1286-1292.

24. Simondon KB, Costes R, Delaunay V, Diallo A, Simondon F, 2001. Children's height, health and appetite influence mothers' weaning decisions in rural Senegal. Int J Epidemiol 30: 476-481.

25. Lohman TG, Roche AF, Martorell R, 1988. Anthropometric Standardization Reference Manual. Champaign, IL: Human Kinetics Books.

26. Simondon KB, Bénéfice E, Simondon F, Delaunay V, Chahnazarian A, 1993. Seasonal variations in nutritional status of adults and children in rural Senegal. Ulijaszek SJ, Strickland SS, eds. Seasonality and Human Ecology. Cambridge, United Kingdom: Cambridge University Press, 166-183.

27. Simondon KB, Simondon F, Costes R, Delaunay V, Diallo A, 2001. Breast-feeding is associated with improved growth in length, but not weight, in rural Senegalese toddlers. Am J Clin Nutr 73: 959-967.

28. Rogier C, Tall A, Diagne N, Fontenille D, Spiegel A, Trape JF, 1999. Plasmodium falciparum clinical malaria: lessons from longitudinal studies in Senegal. Parassitologia 41: 255-259.

29. Rogier C, 2003. Childhood malaria in endemic areas: epidemiology, acquired immunity and control strategies. Med Trop (MARS) 63: 449-464.

30. Friedman JF, Kwena AM, Mirel LB, Kariuki SK, Terlouw DJ, Phillips-Howard PA, Hawley WA, Nahlen BL, Shi YP, ter Kuile FO, 2005. Malaria and nutritional status among pre-school children: results from cross-sectional surveys in western Kenya. Am J Trop Med Hyg 73: 698-704.

31. Simondon KB, Simondon F, 1998. Mothers prolong breastfeeding of undernourished children in rural Senegal. Int J Epidemiol 27: 490-494.

32. Scrimshaw NS, Taylor CE, Gordon JE, 1968. Interactions of nutrition and infection. Monogr Ser World Health Organ 57: 3-329.

33. Schaible UE, Kaufmann SH, 2007. Malnutrition and infection: complex mechanisms and global impacts. PLoS Med 4: e115.

34. Cunningham-Rundles S, McNeeley DF,Moon A, 2005. Mechanisms of nutrient modulation of the immune response. J Allergy Clin Immunol 115: 1119-1128; quiz 1129.

35. Field CJ, Johnson IR, Schley PD, 2002. Nutrients and their role in host resistance to infection. J Leukoc Biol 71: 16-32.

36. Shankar AH, 2000. Nutritional modulation of malaria morbidity and mortality. J Infect Dis 182 (Suppl 1): S37-S53.

37. Prentice AM, Ghattas H, Doherty C, Cox SE, 2007. Iron metabolism and malaria. Food Nutr Bull 28: S524-S539. 
38. Oppenheimer SJ, Gibson FD, Macfarlane SB, Moody JB, Harrison C, Spencer A, Bunari O, 1986. Iron supplementation increases prevalence and effects of malaria: report on clinical studies in Papua New Guinea. Trans $R$ Soc Trop Med Hyg 80: 603-612.

39. Sazawal S, Black RE, Ramsan M, Chwaya HM, Stoltzfus RJ, Dutta A, Dhingra U, Kabole I, Deb S, Othman MK, Kabole FM, 2006. Effects of routine prophylactic supplementation with iron and folic acid on admission to hospital and mortality in preschool children in a high malaria transmission setting: communitybased, randomised, placebo-controlled trial. Lancet 367: 133-143.

40. Nyakeriga AM, Troye-Blomberg M, Dorfman JR, Alexander ND, Back R, Kortok M, Chemtai AK, Marsh K, Williams TN, 2004. Iron deficiency and malaria among children living on the coast of Kenya. J Infect Dis 190: 439-447. 